\title{
Can Allocation by Sortition Resolve the Connecticut Education-Financing Impasse?
}

\author{
A.E. Rodriguez (Corresponding author) \\ Department of Economics \\ University of New Haven \\ 300 Boston Post Road \\ West Haven, CT 06516, United States \\ Lesley DeNardis \\ Department of Government \& Politics \\ Sacred Heart University \\ 5151 Park Avenue \\ Fairfield, CT 06825, United States \\ E-mail: denardisl@gmail.com
}

Received: September 17, 2011 Accepted: October 16, 2011 Published: December 5, 2011

doi:10.5296/ije.v3i2.1138ＵRL: http://dx.doi.org/10.5296/ije.v3i2.1138 


\section{Abstract}

It has been over 40 years since Connecticut amended its Constitution to ensure citizens a right to a free public education. Despite the constitutionally prescribed right, dramatic inequities in educational conditions continued to characterize the state's K-12 educational system, especially between suburban/rural white and urban minority school districts. In the 1970s plaintiffs challenged the prevailing mechanism for allocating education funds with a host of court cases that tackled the thorny question of how much financial responsibility the state should assume to equalize the spending disparities between school districts. Prodded by court decisions, many formulas and approaches have been proposed by the Connecticut General Assembly in response to the various legal challenges yet the state has never fully funded the cost sharing formula nor lived up to the 50-50 cost sharing arrangement envisaged by some policymakers. The situation remains at an impasse with the latest court action, CCJEF v. Rell (2005), to be resolved no sooner than 2014 by most accounts.

Our aim here is to offer an analysis of the decision-making environment that explains the current impasse. We contend that by applying the dual-error framework popular in other social policy settings, it is possible to understand the competing views and beliefs of those groups arrayed in opposition. We claim that the individual and political understanding and policy responses are prone to cognitive heuristics in the manner popularized by Sunstein, Schadke and Kahneman, and Kuran and Sunstein (Kuran \& Sunstein, 1999; Sunstein C. , Cognition and Cost-Benefit Analysis, 2000; Schkade \& Kahneman, 1998). This analytical approach entails a recognition that many policy makers fail to make decisions via the normative model of rational decision-making but rather rely subjectively on emotion, intuitions, biases, character traits, and social and cultural norms in a manner that diverges systematically from the rational model. We argue that differing subjective appraisals of the role of individual agency in the observed achievement gap is at the core of the debate. There are, of course, other inputs into the educational process. But it is this perception of agency that heavily influences the general population's political choices.

The existing institutional framework appears to have cemented this worldview in a situation that has little chance of a meaningful resolution. We note the perplexing conundrum in which Connecticut finds itself and conclude that the problem is a social dilemma in which the parties involved are individually powerless to resolve. Sortition mechanisms - allocation by lottery - have been known to effectively resolve social dilemmas in other domains. We examine the possibility of relying on lots to resolve the allocation of educational monies.

Keywords: School financing, Behavioral economics, Sortition, Heuristics and Biases, Dual-Error framework 


\section{Introduction}

It has been over 40 years since Connecticut amended its Constitution.(Note 1) Among its numerous innovations, the 1965 state constitution unequivocally set forth an equal protection clause and an education clause. (Note 2) The education clause ensures its citizens a right to free public elementary and secondary schools whereas the equal-protection clause bans discrimination or segregation based on race or color

These constitutional guarantees coexisted over the ensuing years with glaring inequities in Connecticut's public education system especially between rural white and urban minority school districts (Eaton, 2006). In the 1970s, in a case known as Horton v. Meskill (1977), plaintiffs challenged the prevailing mechanism for allocating education financing monies alleging it violated the state's constitution. The Court found for the plaintiffs. At the time, the existing system of school financing in the state relied largely on local property tax revenues with a portion coming from the state in the form of a flat per pupil grant. The Court found the existing education financing mechanism unconstitutional because it failed to acknowledge the marked disparities in the wealth among the Connecticut towns and it lacked significant equalizing state support. The Justices reasoned that the system resulted in students in poorer towns receiving an education of substantially lower breadth and quality than that received by students in towns with greater financial capability.

The declaration of an affirmative obligation necessarily compels some judgment. The basic definition of the right is only the prelude to a whole host of subsidiary questions. Left unanswered were how much compensation to provide and who will pay the subsidy. These questions require extensive fact finding and legal interpretation with neither immediate nor unambiguous answers. Indeed, as Professor Richard Epstein (Epstein, Simple Rules For A Complex World, 1995) presciently puts it, "any system of affirmative substantive rights is likely to be dogged by this difficulty.” (p.28) In fact, the Horton Court wisely left it to the state assembly to fashion a constitutionally acceptable remedy.

Numerous formulas and approaches have been proposed by the state assembly (and others) in response to the Court's objections, to no avail (Symposium Connecticut Law Review, 1997). For many, the obligation established by the state Supreme Court has been -despite considerable tinkering - erratically discharged by the state legislature. Fundamentally, we can't seem to agree on how much to pay in "equalizing” state support. In fact, Connecticut has spent the last 30 years embroiled in disputes over precisely this aspect of its public school financing. (Note 3) It has done so under the shadow of continued allegations that inherent inequities in school funding continue to abrogate the same clauses of the state constitution that were found abridged in Horton. (Note 4)

But despite the spirited and bitter court and legislative fights throughout this period - no satisfactory resolution appears to be in sight. In fact, several legal challenges followed Horton. The situation remains at an impasse even with the latest court action- CCJEF v. Rell - which dramatized the continuing social and political disagreement as to the funds necessary to close the performance gap (CCJEF v. Rell, 2010). 
It may be no earlier than 2014 before CCJEF is adjudicated; and there is a sense that CCJEF may not prevail (Note 5) However, it is unlikely that the underlying issue will abate any time in the near or not-so-near future. The performance gap and its associated issues such as the role of the teachers' union, the importance of the nuclear family, the charter and magnet school debates all constitute an integral part of the political grist in Connecticut.

In this paper we explore the possibility of giving 'chance a chance' in resolving the educational financing dilemma. The use of lotteries to make decisions on educational matters has become increasingly popular, as of late (Stone, What Can Lotteries Do For Education?, 2008; Glass, 2006; Dolle \& Newman, 2008; Schwartz, 2005). And it has been naturally followed by a corresponding associated increase in popular and scholarly commentary (Lim, 2011; Mohl, 2004).

Indeterminacy, fairness and incentive effects are typically the major reasons advanced to justify the use of lotteries to make decisions. We neither quibble with nor challenge any of the reasons advanced. Rather, we set forth a decision-making framework within which the education financing decision is to be analyzed, the impasse explained in terms of first principles, and the proposed resolution derived.

Given its permanence in our political environment exploring the decision-making framework that underscores the educational financing impasse may be worthwhile. With a framework in place we can better understand the nature of proposed solutions and the forces aligned in support and those arrayed in opposition. The dual-error framework originates in the decision-making under uncertainty literature (Hammond, 1996). But it is one which has found great resonance across any number of social and legal policy debates (Miller, 2010; Easterbrook, 1984; Hammond, 1996). Indeed, demonstrating the usefulness of this framework in the education financing context is one of our two objectives in this paper. We also draw, based on our analysis, a proposed resolution based on sortition.

The dual-error framework is readily accessible and articulate enough to push our understanding beyond the facile us-versus-them zero-sum nature of the more popular explanation: the impasse arises because the debate and its exponents have pitted the suburbs against urban centers (Dyson, 2004). One party believes it is the target of a shakedown, the other of that it bears the brunt of its counterpart's racial insensitivity (Frahm, 2010). (Note 6)

Our theory also allows us to understand the relevance and limitations of the empirical backdrop of the role of resources in educational performance. In fact, the empirical backdrop at the core of the demand for additional monies expressed in CCJEF is based on a theory of educational adequacy (DeNardis, From Equity to Adequacy: Evolving Legal Theories in School Finance Litigation. The Case of Connecticut, 2010). Whereas the discarded, older theoretical vehicle, an equity theory, would call for uniform funding throughout school districts, the adequacy approach sets a level of funding need to achieve a minimum acceptable educational outcome even at the expense of resulting reverse-discrimination inequities (Koski \& Reich, 2006). Regardless of foundational and empirical coherence, the resolution remains: more monies are required. 
As with all theories the adequacy theory is necessarily imprecise despite its popularity across the nation. Their empirical applicability or relevance may have been demonstrated in a different setting. Its correspondence to a Connecticut setting does not necessarily follow. To draw conclusions in the social sciences requires that empirical evidence be combined with sufficiently strong maintained assumptions about the nature of individual behavior and social interaction. Manski's telling description of what is known as the identification problem is worthwhile (Manski, 2007).

Suppose that, unable to interpret observed patterns of behavior, you seek the expert advice of several social scientists. One asserts that pressure to conform to group norms makes the individuals in a group tend to behave similarly (an endogenous effect). Another theory states that behavior depends on the demographic composition of the group (a contextual effect). A third maintains that persons with similar characteristics choose to associate with one another (a correlated effect). All of these assertions may be consistent with the empirical evidence. The data alone cannot reveal which is correct. Perhaps all are. This is an identification problem. (p. 2)

Moreover, additional uncertainty emerges as a result of the confusion resulting from accumulated social and political battles. Appraising a long-standing dispute over school financing in California, the Little Hoover Commission Report (Little Hoover Commission, 1997) stated:

Yet, a complicated system to pay for schools is exactly what California has. There are obvious parallels to Connecticut. Driven by court decisions, interest group pressure, political compromises and shifting trends, the system has grown increasingly complex without demonstrably moving the State any closer to the goal of a sound education for all children.

Despite the complexity and confusion underscoring the issue of school finance in Connecticut the Court waits for no one. The determinative nature of the legal action compels us to embrace a decision even when its outcome is unknown and possibly unknowable. Fortunately, it is a decision-making framework that we understand well, especially because it calls attention not only to the direct costs or consequences of a decision. Rather, it excels in calling attention to the nature of the counterfactuals - the road not taken - and their associated costs.

On the one hand, a finding for plaintiffs associated with some level of taxation would have a direct cost and an indirect impact on social incentives. On the other hand, if defendants prevail, there are social costs incurred in the poor civic and educational formation of our future citizens; our workforce.

In addition to the direct costs and the cost of unintended consequences, in contemplating either decision we must consider the potential costs of decision-making errors. If we choose to allocate additional monies but the theory fails and the performance gap remains unresolved we incur the costs of a false positive. If we choose in the alternative and allocate no monies it is possible that the discarded theory was correct and by doing so we miss out on the "solution" to the gap and thereby incur the costs of a false negative. In either case, and 
importantly for our argument below, it is the uncertainty or ambiguity accompanying the decision before us that impacts the choices we make.

Within this framework, therefore, we set out to identify the mechanism that minimizes the total social costs including the costs of errors and any costs associated with unintended consequences as well as transaction or administrative costs including legal costs and the costs attributable to the machinations of interest groups.

\section{The Road Ahead}

The decision making framework described above obliges us to pursue a more naïve question at the outset, to probe a little deeper into the foundational beliefs at the root of a fundamental dissension on the role of chance. This understanding is indispensible when making risky or uncertain choices. Herbert Simon (Simon, 1986) stated it as follows:

If we accept the proposition that both the knowledge and the computational power of the decision-maker is severely limited, then we must distinguish between the real world and the actor's perception of it and reasoning about it. That is to say we must construct a theory (and test it empirically) of the process of decision. Our theory must include not only the reasoning processes but also the processes that generated the actor's subjective representation of the decision problem, his or her frame. (pp: 210-211).

To this end we draw on research of many others for illustration. Specifically, we examine the relevance of cognitive biases and heuristics on decision-making processes, features that are especially relevant when one is faced with making a decision amidst a complex environment. Professor Cass Sunstein (Sunstein C. , Foreword, 1995), acknowledges their relevance to the accurate evaluation of choices:

ordinary people tend to rely on heuristic devices - simplified cognitive strategies for evaluating evidence - that lead to large private and public mistakes in risk assessment (at ix).

Decisions in complex environments take longer or require more cognitive resources than decisions in simple situations. Intuitively, the extra effort required to deploy a more sophisticated strategy is a cost that often outweighs the potential benefits of enhanced accuracy. These tradeoffs thus constrain the types of strategies that are chosen.

Perhaps the most commonly invoked explanation for bias is that they are a byproduct of processing limitations. Humans are boundedly-rational: their information processing time and ability are limited. As a result we use shortcuts or rules of thumb that are prone to breakdown in systematic ways. This explanation can be traced to the seminal work of Tversky and Kahneman (Tversky \& Kahneman, 1974).

We revisit the role of chance in education outcomes which we hold forth as the focal point of our argument. We claim that impasse embodies differing interpretations on the role of chance and that most of us rely on an unduly narrow analytical frame to the problem. We acknowledge that extending this agent-level heuristics to aggregate decision-making 
institutions is necessarily speculative. But an important part of the exploration is to determine whether the organizational context is likely to enhance or inhibit the individual heuristics. Succinctly, when decisions are taken infrequently there is little room for feedback and sorting, the learning which acts as an aggregate corrective to deviations from rational behavior at the agent level.

We conclude that firmly held beliefs are swayed with difficulty. We thus turn to the plausibility of allocation by sortition - a decision-making tool easily understood in its practice. A lottery eliminates or avoids the traps set by the cognitive biases inherent in complex decision-making.

Our argument unfolds as follows. The next section provides a succinct, historical overview of the legal and legislative battles underscoring education finance reform in Connecticut. In the third section we set forth the focal point of the analysis - the asymmetrical understanding of the role of chance in educational performance. We then examine the relevance of narrow framing in the decision whether to support the plea for incremental monies. We then explore the lottery as a mechanism for allocation. In the last section we offer concluding comments.

\section{The Legal History}

Although the original legal theory underscoring Horton v. Meskill (1977) spoke of equalizing educational resources across towns and cities, the debate has resurfaced lately in CCJEF $v$. Rell as a concern over the right to an "adequate" education (CCJEF v. Rell, 2010). Despite the semantic shift, the controversy has always been over acceptable remedies for closing the observed disparity in educational performance - the achievement gap - across racial groups in the state. (Note 7) And although there have been other proposals seeking to address the performance gap, the present dispute has been, and continues to be, a battle for monies. (Note 8)

As in many other states, racial minorities in Connecticut consistently underperform their white counterparts (CONNCAN, 2010) . According to the U.S. Department of Education figures, Connecticut has the largest achievement gap between poor and more affluent students in the nation, with poor students positioned three grades behind their affluent cohort (Note 9). As in many other states, racial minorities in Connecticut tend to cluster in urban areas; in Connecticut these clusters are found primarily - but not exclusively - in the cities of Bridgeport, New Haven and Hartford, and in the towns and suburbs ringing these cities. (Note 10) In addition, these urban areas are comparatively and often markedly poorer than the rest of the state. Because the proposals tend to result in the diversion of funds from rural townships towards urban areas, this segmentation effectively pits State Assembly representatives from the rural - mostly white - areas of the state against those representatives from primarily urban-dwelling, minority groups. The impasse at the legislature thus reflects the geographic political calculus invoked by the fragmentation of decision-maker-cum-voter interests.

\subsection{Horton and Its Progeny}

School finance reform has been one of the most controversial and contentious issues in public 
policy over the last thirty years not only in Connecticut but across the nation. Public schools have served as battlegrounds over fundamental questions of equality, and access to social and economic opportunities. Since the historic decision rendered by the California Supreme Court in Serrano v. Priest (1971) equated public education with a fundamental right, a wave of legal and legislative reforms have swept the nation. Connecticut has not remained immune. Following the lead of California, a Connecticut group filed suit in the early 1970s arguing that Connecticut's heavy reliance on the property tax to finance public schools was unconstitutional.

The Connecticut Supreme Court in Horton v.Meskill (1977) found in favor of the plaintiffs. The Court directed the General Assembly to fashion a plan to equalize spending between school districts. Thirty years plus and numerous attempts later, the goal of reducing the performance gap has not been achieved. In fact, despite modest strides in equalizing spending, the gap between rich and poor districts appears to have widened. In examining what she termed as "Horton's Odyssey" to describe the fortunes of the school financing battles, DeNardis finds the State Assembly's managing of the charge - an "apparent policy failure (DeNardis, Horton's Odyssey: The Politics of School Reform in Connecticut, 2010).” (Note 11)

The lion's share of the policy failure rests with the Connecticut General Assembly. As the body prompted by court decisions to design an equalization plan, much of the responsibility can be squarely placed at the legislature's doorstep. While the design of the equalization plans differed depending on whether Democrats or Republicans controlled the General Assembly, what did not differ greatly was a notable reluctance to fully fund equalization schemes. Both political parties seemed to be equally concerned with cost containment yielding to important political realities. Gubernatorial inaction, legislative recalcitrance and looming financial and fiscal realities all conspired to doom school finance reform in Connecticut. (at 275).

In Horton v. Meskill the Connecticut Supreme Court acknowledged the notion that the bad moral luck that has befallen its minority brethren generates an entitlement, a community obligation. The Court said that a system of school financing that relied on local property tax revenues without regard to disparities in town wealth and that lacked significant state support was unconstitutional. The conundrum emerged because the Court in effect failed to address the necessary priors for government action: who should pay, who should receive, and how much. The practical impossibility of agreeing on these set of questions inevitably would result in further legal action.

It soon arrived. In a related case, Sheff v. O'Neill, the Connecticut Supreme Court ruled that the state had an affirmative obligation to provide Connecticut's school children with a substantially equal educational opportunity and that this constitutionally guaranteed right encompasses the access to a public education which is not substantially and materially impaired by racial and ethnic isolation (Sheff v. O'Neill, 1996). The remedies implemented in the wake of the Sheff proved to be insufficient. Meanwhile, school financing reform took center stage again with the suit filed in 2005 by the Connecticut Coalition for Justice in 
Education Funding (CCJEF) on behalf of several Connecticut students and families. Plaintiffs again argued that the state's failure to properly fund public schools inadequately prepares students for higher education and employment opportunities. CCJEF contended that the achievement gaps between students in the inner cities and students of the more affluent suburbs of the state was proof that quality education is not present in Connecticut. Upon that premise, plaintiffs' theory rested on noting disparities in preschool classes, libraries, technology, hours of instruction, class size, textbooks, special education programs, and curriculum as evidence that the state has failed their obligation to provide a suitable educational opportunity (Lohman, 2005). Furthermore, CCJEF maintained that the state's failure to support a suitable public education system has disproportionately impacted African-American, Latino, and other minority students.

The state moved to strike the adequacy claims, arguing that the state Constitution does not confer a right to "suitable" educational opportunities, and does not guarantee equity or parity of educational achievement or results. The Connecticut Superior Court concurred and ruled in 2007 that the state constitution does not assure a minimum standard of quality for public education.

CCJEF, however, immediately filed an appeal and was joined by the support of many in the legal education community, including the Lawyers' Committee for Civil Rights Under Law, who filed a friend of the court brief in 2008 on behalf of the Connecticut State Conference NAACP and the Center for Children's Advocacy.

The Connecticut Supreme Court reversed the lower court's ruling. It relied on Horton $v$. Meskill, where the Court found that under the state constitution, the state must provide a substantially equal educational opportunity to its youth in its free public schools.

The court also paid considerable deference to Sheff $v$. O'Neil, where it had held that the courts have a role in ensuring that students receive the fundamental guarantee of an education. The court found that "the fundamental right to an education is not an empty linguistic shell" and must meet modern educational standards.

\section{The Dual-Cost Framework for Understanding Policy Decision-Making}

Judge Richard Posner observes: the consequences of the law are often unknown, so that feedback is impossible. Hence the justification of legal decisions - the demonstration that a judicial decision has been proved correct, is often impossible ( (Posner, 1993)

Sensitivity to the dual-cost or error-cost character - the names are used synonymously - of decision-making under uncertainty, are increasingly found across any number of fields. Examples of discussions of the likelihood and associated costs of errors range from rain forecasting, to the security of computer operations to airport screening protocols (Savage \& Wainer, 2008). Sadly, the framework's relevance and insightfulness as an ex ante framework is often discovered - more often than not - in the wake of regrettable or unfortunate incidents such as an earthquake, terrorist attack, or hurricane. Still, its present reliance as a formal analytical methodology in the appraisals of decision-making in legal, social and public policy settings is sufficiently widespread to be considered if not conventional, certainly well 
ensconced within the mainstream.

There is an inherent uncertainty in the decision-making process. The dual-cost framework reflects the unavoidable reality that policy decisions - as do all screening tests - filters or appraisals that presume to identify or diagnose a binary outcome (true, false; guilty, not guilty; ill, not ill, etc.), may do so incorrectly. And it may do so, incorrectly, in one of two ways. Consider the example of a medical test which screens for a particular condition. Two kinds of possible errors result from these processes - false positives and false negatives. A false positive in medical screening occurs when the test diagnoses a patient as having the disease, when in reality the patient is disease-free. It is positive because the test indicates that the patient has the disease, and it is false because the patient, in reality, does not have the suspected illness. A false negative in medical screening occurs when the diagnostic test finds no evidence of a disease in a patient who is, in reality, disease-ridden.

Importantly, a decision based on a diagnostic test should not depend on the rate of false positives or false negatives alone. Errors are costly. A positive outcome will possibly trigger further testing, and perhaps stressful and possibly painful preliminary treatment. In our medical-screening example, the reporting of a positive test result to a patient confers emotional anguish, anxiety, frustration, inter alia, intangible costs no less relevant and possibly more copious and substantive than the monetary cost of treatment. Also, the impact or utility of the costliness of the errors varies across individuals and by accretion, social groups. A cancer diagnosis, frightful as it is, would not have the same impact among us all; some weather adversity with stoicism, others less so. Thus, we appraise the utility of a medical test outcome rather than only the error rate to account for the intangible significantly real costs.

The dual-error framework applies, mutatis mutandis, with equal rigor to our educational financing impasse. The elements of decision-making can be visualized in the following diagram which sets forth the outcomes between expenditures and performance.

Table 1.

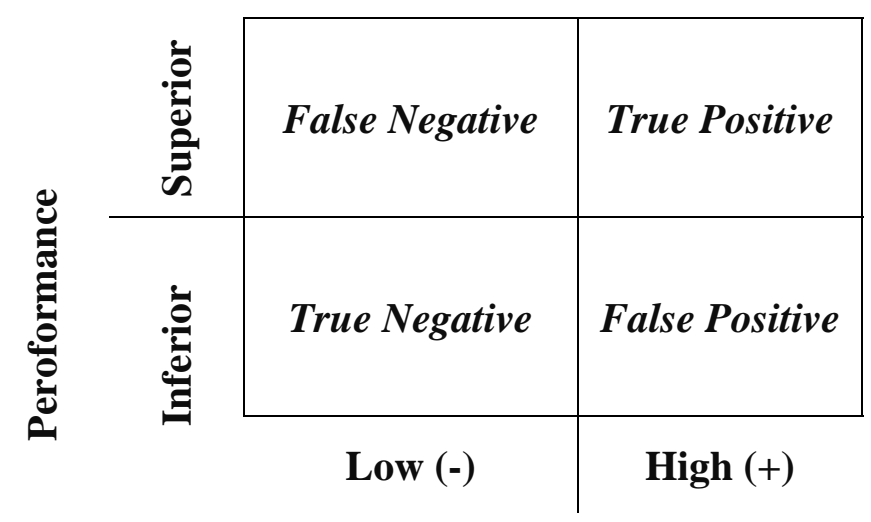

\section{Expenditures}

The diagram frames the decision on the underlying empirical relationship between a 
measurable rubric of school spending such as cost per pupil or a similar metric, - and revealed outcomes in terms of some measure of performance. The vertical line represents the existing segmentation in the level of school funding- labeled dichotomously for purpose of illustration in the graph as high and low spending. The measured performance representing broad, economy-wide outcomes or more immediate measures of academic performance can be seen along the vertical axis. The realized performance, again, for purposes of illustration characterized in the table above by the two segments labeled 'Inferior' and 'Superior.'

Thus, the level of spending in combination with resulting student performance results in four possible outcomes, reflecting a similar interpretation discussed above using a medical screening test as the archetypical example. If spending is high and it results in successful performance it is considered a True Positive outcome. If the spending is high but the outcome ascribes to a low performing student - the outcome is considered a false positive. By the same token when expenditures are modest it may have been associated with a high performing student if the outcome a result considered a false negative. And last, if the spending is considered below and is associated with a poor performing student, the outcome is considered a true negative. A fundamental point is that a compensatory relationship exists among the proportions or probabilities, of the four outcomes (Swets, 1992). Specifically,

Exactly where the positive criterion is set determines the balance among these proportions. If a low or lenient criterion is set, the proportions of both true-positive and false positive outcomes will be relatively high and the proportions of both true-negative and false-negative outcomes will be relatively low. The converse is the case when a high or strict criterion is set. (at 523)

The tradeoffs involved in the financing debate are equivalently arrayed but act in opposite directions because of the zero-sum nature of school finance: increased allocations to one group reduce the monies available to the second group. Those who advocate more monies for minorities argue that it enhances their academic performance thereby impacting their futures along two broad lines. First, increased monies will enhance their ability to earn a good-living in the future. Second, increased academic performance reduces their chances of dropping-out of school; dropping-out is associated with lowered lifetime incomes, an increased probability of criminal activity, in effect increasing their chances of depending on state largesse in the future.

Those opposing the income transfers offer equally compelling arguments. Reduced monies reduce the chances of success of above-average students preventing them from reaching their full potential and depriving society of the potential gains of their future efforts, to the detriment of us all. Similarly, the increased tax burdens on the suburbs required to finance the increased monies combined with the sense of being victimized by a state action that has been unjustly hijacked by the politics of race tend to erode entrepreneurial initiative and risk-taking. Again, these have future economic repercussions for us all.

Hammond notes that each of the four regions in table of outcomes above will develop its own political constituency (Hammond, 1996; Stewart, 2000). In the presence of irreducible uncertainty, the groups arrayed in opposition will seek to either shift or hold firm the level of 
expenditures.

Those advocating increased spending have minorities as their constituency. They emphasize their plight and the adverse consequences and disregard or diminish the plausible occurrences of those who oppose them. Conversely, those opposed to further redistribution argue the opposite scenario with equal vehemence and disregard, disbelieve or discount the proffered counterfactuals. There is an additional consequence that may be as costly as any of the competing scenarios- the interest group competition that devolves into considerable dissipation of wealth.

Although the framework applies, mutatis mutandis, with equal rigor to our educational financing conundrum, there are important similarities as well as crucial differences worth clarifying between medical testing and social policy generally. In medical screening protocols, we appraise the size of breast nodules via imaging technology, for example, because there is a well-documented relationship between the appearance of breast nodules and the emergence of breast cancer. Such a relationship between incremental monies for schooling and outcomes exists but is less precise, in a statistical sense, that the medical one.

There are two sources of error in this framework (so far). First, the imaging machine itself is imperfect and wholly incapable of avoiding error in its appraisal. Still, the sensitivity of the particular medical test can be gauged by appraising its performance against a "gold standard." This calibration of the machine's capabilities, usually completed by a device manufacturer via the use of samples with known outcomes, allows for the determination of the instrument's ability to correctly identify whether a particular illness or condition is present or not. Thus, the accuracy of a medical procedure can be established by reference to an 'objective' reality. (Note 12) Second, the metric, or statistic selected to provide the causal link to the outcome may itself boast an imperfect association. Thus, the presence of a nodule does not automatically result in cancer.

When it comes to social policy the process is considerably more error prone. Gauging and appraising differ in quality and setting. No objective reality can be discerned, especially one under the controlled settings under which a gold standard is established to calibrate machine testing protocols. In fact, some scholars, aware of the scant data-driven results have advocated more instances of social policy controlled experimentation. Even those administering medical screens do not know, at the time of actually performing them, who has the disease, and who does not; otherwise there would be no need to "test." Thus, there is always some likelihood that a test set forth to determine whether a patient has a disease, or whether a particular weather forecast was a hit rather than a miss may result in the incorrect answer - an error.

\section{Educational Performance and Chance}

Most people, when pressed, would acknowledge that individual agency and chance play a role in the outcome of many activities: sports, business, investments and education - but nonetheless, have a poor sense of the relative contribution of each (Mauboussin, 2009). When it comes to schooling, to many, personal success or failure in school depends on individual 
agency: personal initiative and responsibility (Chua, 2011). (Note 13) To others, educational performance depends largely on chance.

This interpretive contrast represents bookends of a spectrum where views differ on the weight ascribed to each component in the resolution of outcomes. Libertarians, placing greater supremacy on the individual minimize the influence of chance whereas egalitarians view the fortunes of minorities as heavily beset by chance or "moral luck" (Nagel, 1976; Epstein, Luck, 1988). These competing appreciations of the role of chance have generated deep-disagreements over the role of government in many policy spheres and resulted in conflicting goals in American education policy (Epstein, Decentralized Responses to Good Fortune and Bad Luck, 2008).

This understanding of the role of agency versus chance is a foundational belief - rarely informed by data or facts. It would be for Douglass North an instance of a mental model that sits astride a shared framework of mental models (North, Institutions, Instutitional Change and Economic Performance, 1990). These provide groups of individuals with both an interpretation of the environment and a prescription as to how that environment should be ordered. To North and other institutionalists "beliefs" and "perceived reality" are critical in shaping the prospects of institutional change (North, Understanding the Process of Economic Change, 2005). Our perceptions of reality - of the nexus of cause and effect relationships that govern the physical and social environment - will influence the types of beliefs that we form. "Beliefs" are propositions to which we assign truth value; these include positive beliefs about cause and effect relationships as well as normative beliefs about justice, virtue, and other considerations. These beliefs shape and inform the kinds of institutions that emerge, the constraints governing institutional evolution, and the organizations that form in response to the institutions. Generally, organizations enact policies, policies create outcomes, and these outcomes alter our perceptions of reality. Over time, institutional, economic, and social change will be slow, incremental, and, in many respects, fundamentally unpredictable (Carden, 2009).

As with all such closely-held beliefs it would matter little if we were given applicable information to illustrate its relevance or lack thereof. In an example of both optimism bias as well as self-serving bias, if and when confronted with critical data we are likely to interpret it in a manner consistent with our own views. Moreover, we are likely to skew the evidence favorably towards our interpretation of events. Perhaps more striking is the fact that unaware of our skewed information processing trait we are prone to remain smug in our conviction that our judgments are free of bias.

The libertarian emphasis on individual agency lie in general opposition to an expansion of the state's involvement in social policy including education policy. Egalitarians tend to believe that government has an obligation to compensate for individual deprivation that occurs naturally through no fault of their own (Epstein, Decentralized Responses to Good Fortune and Bad Luck, 2008). This understanding sets a framework for advocating for an expansion of the role of the state on social policies. Not surprisingly, this advocacy forges an education policy designed to remedy past social inequities. It does so because recognizing the relevance 
of moral luck logically leads on to question the source of the disadvantage which produced present-day unequal educational opportunities.

The seemingly impregnable path dependency underscoring the educational process is insidious and debilitating not only to minority groups but to all of us. Indeed, the legal terrain is testimony to the collective sense that the historic patterns of behavior can be remedied by redistribution mechanisms. Education after all, is the great equalizer in American society. Yet, while we appear to agree on the redirection of educational resources we differ on the amount.

The rationale of singling out for scrutiny the evaluation of the environment in which students learn - as plaintiffs do in CCJEF v. Rell - is seemingly sensible. It appears commonsensical because we feel physical facilities constitute a necessary input. What is not self-evident at first glance is that physical facilities are not a sufficient input into the learning process. In addition, faculty credentials are appraised to determine whether they reflect required subject-area expertise. Libraries, classroom conditions and computer facilities support academic efforts.

Plaintiffs in CCJEF v. Rell claim rested on an urban v. rural comparison of the various education physical inputs. By singling out differences in the composition of inputs they were effectively setting forth an educational services production function based on fixed inputs (Hanushek, 2002). Put differently, that a particularly desired level of education outcome demanded an equal composition of inputs. Rather, it is sensible to think that an education output production function could achieve comparable levels of output with varying levels of inputs - in effect, recognizing the possibility of substituting, at the margin, some inputs for another. For example, it is entirely possible that Lay's potato chips contain certain level of energy as input whereas some other companies substitute less energy to achieve comparable products in the sense that across the consuming public these competing products are de facto substitutes. Obviously, this argument can only be stretched so far. At some point, to effectively deliver educational services a basic level of a particular input is clearly necessary.

An adequate environment is necessary but not sufficient because education performance varies dramatically based on the combination of provider outputs and user inputs. But education performance is the product of a service markedly different from other services in our economy. Take another example. The "outcome" derived from the services of a banker, a plumber, or a car mechanic whiles susceptible to variations in the skill of the provider, remain relatively homogenous across service purchasers: either the toilet works or it doesn'tit really doesn't matter whether some users flush harder than others.

Educational performance is different because chance - in the manner of variation in the early childhood skills that a child brings with him constitutes an unavoidable input into the process - one that necessarily devolves into varying levels of performance even if all other inputs were similar across the board. Kids who commence their schooling having benefited from parents' careful nurturing, devotion and concern - traits typically positively associated with higher income level families - are likely to perform better than those who come from environments in which neglect, poor language skills, and little or scant discretionary time available for kids (Currie, 2011). These latter traits are in fact, inversely associated with less 
affluent and poor families. The lack of observational equivalence between urban and rural children makes it close to impossible to fully appraise the performance of a particular system. Indeed, the appraisal of performance is a task fraught with countless difficulties under normal circumstances only to be made worse if one fails to account for these resolutions of moral luck.

How should society manage the educational odds its citizen's face? The various alternatives possible can result in a service or a disservice to its citizens. We assume that a reduction in the arbitrariness affecting human life is a desirable thing. Yet it costs more for the state to remove luck's influence. This conclusion proceeds from two premises. The first is that disaggregating the effects of luck (unchosen inputs) from effort or agency (chosen inputs) is often an impossibility. In fact, to pretend otherwise is a cognitive fallacy what 2002 Economics Nobelist Daniel Kahneman refers to as a 'focusing illusion" (Schkade \& Kahneman, 1998) and Sunstein 'system-neglect' (Sunstein C. , Cognition and Cost-Benefit Analysis, 2000). Kahneman notes that "when people are induced to believe that they 'must have' a good, they greatly exaggerate the difference that the good will make to the quality of their life." Moreover, the focusing illusion, according to Kahneman "is greater for some goods than for others, depending on the extent to which the goods attract continued attention over time.” When it comes to education:

Education is an important determinant of income - one of the most important — but it is less important than most people think. If everyone had the same education, the inequality of income would be reduced by less than $10 \%$. When you focus on education you neglect the myriad other factors that determine income. The differences of income among people who have the same education are huge. (Kahneman, www.edge.org, 2011)

Where chance and agency are intertwined as much as they are in education, the costs of separating them may be greater than the gains from responding optimally to each component. Second, luck corrections cannot be successfully unbundled from politics - once characterized by rent-seeking and influence peddling. As will become clearer later, we argue that allocation by lottery is a reasonable response to educational fortuity and superior to government correctives.

\section{The Current Impasse as an Embodiment of Cognitive Limitations}

The potential direct liability of increased redistribution via school finance - were CCJEF to prevail - entails the likelihood of higher taxes at the expense of the more affluent, white suburbs. The argument in support of the increased monies is as follows: we either pay now or we pay later. Neglect and disregard for the human aspects of the performance gap will condemn these kids to future menial jobs and compel many into a life of crime. We - as a society all lose if we do not adequately train our workforce for the economy of the future.

The argument in opposition to the redistributive scheme paints an equally dire picture. Higher taxes increases the costs of doing business, depresses initiative and entrepreneurship, impairing the state and society's prospects for continued growth in the future. By opting for redistributive schemes with unproven results we handicap our present and especially our 
future competitive abilities.

When we debate the issue of increased redistribution we place greater weight on believing our side of the argument. We not only seek confirming information but disproportionately weigh it while at the same time discounting contrary or disconfirming evidence. These are routine descriptive human cognitive processes.

The relevance of cognitive processes embodying short-cut rules for decision-making are well-known. Writing over 20 years ago, Robert Frank (Frank, 1988) noted that "it is no longer controversial to say that we come into the world equipped with nervous systems that predispose us to behave in particular ways.” (at 5-6)

When confronting a decision fraught with risk, with uncertainty or ambiguity as to the consequences of our decisions, we routinely fail to recognize the systemic nature of individual decision-making. We tend to assume that any change resulting from a particular decision before us alters only the issue of immediate interest to us - a choice architecture that was established in the framing of the problem. Implicitly, we assume it does not affect other constituent parts. And if we acknowledge any secondary attributes, links or feedback effects we severely discount their relevance or correspondence. The capacity of human beings when it comes to the collection, storage, organization and use of knowledge involves costs and time - and this naturally limits the scope for logical choice by individuals. By neglecting the associated impact on other parts of the system, we tend to discount or neglect the possible wide-array of tradeoffs incurred.

The fact that people when faced with explicitly probabilistic prospects, tend to frame their decision problem narrowly was established a while ago by Heiner, March and Shapira and others (Heiner, 1986; March \& Shapira, 1987). It is indispensible for us to understand the relevance on decision-making of such a narrow frame because otherwise, there would be no meaningful controversy over the varying understanding of the relevance of moral luck, only shortsighted and inefficient outcomes; at least in the short run. With careful tinkering and perfect knowledge and information, any evident systematic error would ultimately disappear. But the fact is that there are various associated cognitive issues that impair this process precisely because we have neither perfect knowledge nor a well-disposed decision rule.

Consider the typical reaction we all display when confronted with evidence that is contrary to one's heartfelt beliefs. Taber and Lodge describe it accurately (Taber \& Lodge, 2006): research findings confirming a hypothesis are accepted more or less at face value, but when confronted with contrary evidence, we become "motivated skeptics," (Note 14) mulling over possible reasons for the "failure", picking apart possible flaws in the study, recoding variables, and only when all the counter arguing fails do we rethink our beliefs. ...One negative consequence of this practice is that bad theories and weak hypotheses, like prejudices, persist longer then they should.

This conclusion emerges from work in which Taber and Lodge (2000) examined the prior attitudes and attitude changes of students when exposed to political literature for and against gun control and affirmative action. Their model, which they called motivated skepticism helps 
explain when, how, why and under what conditions citizens are prone to be biased political information processors.

The study found support for the following hypotheses:

1. Prior attitude effect. Subjects who feel strongly about an issue - even when encouraged to be objective - will evaluate supportive arguments more favorably than contrary arguments.

2. Disconfirmation bias. Subjects will spend more time and cognitive resources denigrating contrary arguments than supportive arguments.

3. Confirmation bias. Subjects free to choose their information sources will seek out supportive rather than contrary sources.

4. Attitude polarization. Exposing subjects to an apparently balanced set of pro and con arguments will exaggerate their initial polarization.

5. Attitude strength effect. Subjects voicing stronger attitudes will be more prone to the above biases.

6. Sophistication effect. Politically knowledgeable subjects, because they possess greater ammunition with which to counter-argue incongruent facts and arguments, will be more prone to the above biases.

All appear to be operative in our processing of the elements of the decision before us.

The system neglect heuristic may be further decomposed. We tend to overestimate the extent to which performance is due to agency, free will or disposition and underweight the extent to which performance depends on the various environmental factors surrounding an underlying situation - including the role of chance. In this sense, the behavioral appraisal of educational outcomes constitutes a manifestation of the heuristic process of representativeness, in which judgments of the likelihood of an event are thought to be based on assessments of how well and event represents or matches particular prototypes.

The basic thesis of the Heuristics and Biases literature is that people rely on simple habits of the mind when confronting decisions under uncertainty. In routine commonplace ordinary life, we pride ourselves on being logical and sensible decision-makers - capably and rationally adding up costs and benefits of the choices before us and thereby willfully choosing the most advantageous alternative. Yet, real-world decision-makers frequently depart from the prescriptions of normative decision-theory. The human decision maker systematically and predictably deviates from how it should behave. Most of us do not adhere to principles of deductive logic. Despite our explicit or implicit claim, we resist relying on broad-based optimization strategies (such as cost-benefit analysis or expected utility maximization) as a means of addressing questions of risk, equity or morality in favor of simple rules of thumb.

Educational politics thrives on attention-grabbing events. Plaintiffs and supporters turn to public appearances with children. They craft slogans to make their positions trigger emotional connections to underlying impressions - rendering them easily understood and 
therefore remembered. Attention is drawn to salient stimuli that contrast with other stimuli in the environment. Attention is drawn to vivid stimuli, such as stories of personal experience and emotionally arousing information ( (Nisbett \& Ross, 1980; Hirshleifer, 2007). The intent is to spur favorable actions drawing upon the "availability bias" i.e. the tendency to overestimate the likelihood of occurrence of the salient or recent events that come to mind easily.

\section{Allocation Mechanisms}

Policy issues cannot be resolved at the theoretical level because different theories offer guidance often at cross-purposes. It is a practical impossibility to rationally decide ex ante on the level of monies necessary to address the performance gap. But even if we agreed on first principles - it is not clear what mechanism or formula we would use to allocate the monies. Should the monies be allocated based on merit, on need, or on a first come first served basis? Should we establish a market? In this section we review the typical mechanisms available to groups and governments to allocate scarce resources.

Goods or benefits are scarce when demands exceed available supplies; thus, every applicant cannot receive them. The more commonplace means of allocation include the market, merit or need and temporal priority (Greely, 1977; Calabresi \& Bobbitt, 1978). In this section we examine their merits and limitations.

There are, of course, markets. A market mechanism translates demand and ability to pay into a system that allocates goods to their highest-valued use. Market allocations have a special virtue: left unfettered, the workings of the free market lead to an optimal allocation of resources under certain conditions. In this idealized world, all agents have perfect information. All buyers and sellers know what all the other buyers and sellers are willing to pay or to sell for; and they know that everyone else knows that they know. All agents in are perfectly rational. An agent is rational if decisions are based on (a) a known set of goods or alternatives and their corresponding outcomes; the goods or alternatives not only constitute such essentials as food and clothing but also include various forms of services; (b) a well-behaved preference rule in which more counts for better, when judged by subjective standards; and (c) a maximization criterion.

The intensity of our individual preferences differ across goods, as it turns out. But it is this divergence in preferences which allows for gains from voluntary trade. And trade, especially in the absence of transaction costs, improves each individual's position. Markets, in this highly stylized world serve as benchmarks against which other allocations are gauged.

The real world is not like this. In the real world decision-makers do not have complete information. Rather, they have private, limited, localized information which constitute costs. And as we discussed above, humans are not perfectly rational either. They may want to maximize their self-interest, but it is not always clear how this can be accomplished. Often, as a result we settle for sub-optimal outcomes.

There are allocations based on perceptions of merit or need. It requires the selection of a particular identifying decision metric; an ordinal ranking of all participants based on their 
'score.' And last, a cutoff or threshold separating those who obtain the benefit and those who don't.

One can rely on first-in-time rules: (first-come, first-served) which often reward knowledge, speed \& desire (unrelated to wealth). Often these rules are internalized in norms of behavior, within a culture or tradition. Indeed, because it saves us from the potential disutility of 'thinking' we can simply turn to how we have been doing things all along and rely on customs, mores and traditions.

These mechanisms economize on transactions costs in varying degrees and thereby reduce the amount of cognitive demands on our decision-making. Conventions, mores and traditions enable decision-making without thinking much about them and overcome the operational and transactional difficulties in attempting to implement an optimal solution. First in time is clearly suboptimal. It does not account for the strength of preferences. But the amount of work it would take to figure out the ideal allocation would far outweigh the benefits from such an allocation. It facilitates the coordination problem by providing a roadmap to both sides of a transaction as to the most likely decision a counterparty will take.

\subsection{Allocation by Randomization}

For most people, chance is a familiar but unexamined concept, a word that means different things to different people and different things to one person depending on context. We dream of winning the lottery; we despair of the possibility of being in a plane crash. Or we speak of a chance encounter, by which they mean unplanned, unanticipated. This belief can be captured in a simple number, a probability or odds of something happening (Mauboussin, 2009).

Chance can be a menace while simultaneously proffering a hopeful opportunity. When investing, for example, we speak of the chance of losing money. Yet, at the same time convince ourselves that our instincts, our skill or our lucky predisposition trounce all. Chance is a thing that upsets our investment plans, makes us poor where we hoped to be rich. We weigh risks, compare stocks with bonds, real estate with treasuries. Most people have no idea how to do that systematically and numerically, but they accept that chance is, somehow, involved in their personal investments. Consider the alternative - they have only themselves to blame for a lousy investment - bad luck makes a handy scapegoat.

How prevalent are lotteries in decision-making? Lotteries are not uncommon. They are routinely used for example, to decide who sits on a jury, who receives scarce medical treatments, and who gets to attend magnet and charter schools. Despite their presence, and upon reflection, people do not like having their circumstances decided by lottery. This is especially true if most people cling, as most of us do, to the idea that outcomes must exist for particular reasons - ascribing a cause-and-effect relation to matter in which such a relation may not exist. This invites the conclusion that 'solving the problem' is a matter of technique rather than chance, and therefore the decision can be made in an informed and principled way, rather than by lottery.

What about those used to allocation by another system, especially if they were consistently 
"winners" in that system? Transitioning to a lottery system challenges them to admit that the system in which they often won was unfair, and that they were, therefore, unfair winners.

Are there general principles determining when a lottery is or isn't an appropriate way to distribute benefits? Peter Stone points out that there are many ways to distinguish among people, some of which will be irrelevant to solving whatever distribution problem is at hand. (For example, though it is possible to distinguish among people by skin color, many would consider this distinction irrelevant when, say, determining which young adults to conscript into the military.) Still, some distinctions will be relevant to solving that distribution problem. (For example, distinguishing between able-bodied young adults and disabled ones might be important for deciding whom to conscript.) In light of this, Stone's heuristic for deciding when a lottery is appropriate is this: If, after exhausting all relevant distinctions among potential beneficiaries, it remains undetermined how to distribute the benefit in question, then use a lottery. This helps prevent irrelevant distinctions from infecting distributors' decision-making (Stone, What Can Lotteries Do For Education?, 2008).

Stone also thinks that only a particular kind of benefit, which he terms "lumpy," is appropriately distributed by lottery. Roughly, a lumpy benefit is one that can't be divided among an arbitrary number of beneficiaries such that everyone benefits to some degree. For example, suppose there are one hundred free tickets to the movie theater. If one hundred and one people want a free ticket, someone must go empty-handed, for it's impossible to distribute one hundred tickets among one hundred and one people without tearing (and thereby invalidating) some of the tickets.

\section{How Would an Allocation-by-Lottery System Work?}

The blindness of a lottery outcome means that it will sometimes seem unfair. Yet it is precisely because the lottery is blind that we often believe it to be the fairest means by which to resolve an essentially unfair situation - such as when a disadvantage or burden exists which must be distributed but which cannot be equally shared (Duxbury, 1999).

It may seem that we generally agree when to rely on a lottery as the allocation mechanism of choice. Many scholars have examined the nature of lotteries and the reasons why people might wish to employ lotteries to make a wide variety of decisions (Duxbury, 1999; Elster, 1989; Goodwin, 2005; Kornhauser \& Sager, 1988; Broome, 1984; Sher, 1980; Stone, The Logic of Random Selection, 2009; Stone, Three Arguments for Lotteries, 2010). The fascination with lotteries as a source of entertainment or guidance has inspired many works of fiction (Rhinehart, 2001; Borges, 1998; Jackson, 2009).

It appears we resort - or have resorted - to lottery - or sortition - for allocating organ transplants, judicial case assignments, tax audits, hunting licenses, military service, and jury pools, among others. For most, allocation by sortition seems to be available as a tie-breaking device. It is brought forth when two or more people have equal claims to a scarce good or service that cannot be divided among them by appealing to other allocation mechanisms. (Note 15) But others argue that a lotteries' appeal lies not so much on its probability-based fairness but rather in its ability to reduce the intensity of self-interested activity by lobbies 
and interest groups in a society. Rent seeking groups expend resources to divert ostensibly "free" benefits to their constituents (Lockhard, 2003). The aggregated resources spent via rent-seeking activity can easily exceed the aggregate benefits effectively rendering the situation a net social loss.

Reliance on sortition in many fields appears natural (or, at the very least, tolerated) largely because it has been the traditional or customary allocative mechanism for that particular choice. Interestingly, we have more recently turned to sortition for decision-making in "non-traditional" fields where the use of a lottery would have appeared unthinkable to manyeven a few years ago. The right to immigrate to the United States, relies no longer on national quotas, racial preferences or any other such measures used in our past history. Rather, immigration policy relies on assignment via a "green card lottery.” We have heard proposals to resort to lottery in the assigning of high-risk drivers to insurers (Mohl, 2004). Beijing traffic authorities turned to lotteries to allocate a greatly reduced supply of new license plates in an attempt to reduce congestion and pollution ( Lim, 2011). In the field of education, for example, there is Race to the Top, a federal education program which allocated - via a lottery-flavored race - federal monies to states.

Lotteries are not only common but often mandated when choosing students for admission to oversubscribed charter and magnet schools (Stone, What Can Lotteries Do For Education?, 2008; Dolle \& Newman, 2008). Indeed, a subtext in Davis Guggenheim's, popular Waiting for Superman and Madeleine Sackler's The Lottery, films which document the hope, agony and disappointment of children soliciting admission into charter schools, renders selection by lot in an unflattering light yet is unequivocally tolerated because on its impartiality. Schwartz points to the poor performance of SAT scores and grade point averages in predicting college performance. Lotteries are proffered as a mechanism that would resolve the problems with-in school admissions (Schwartz, 2005) .

One would naturally have to take some account of need in forming the pool of those elegible among which to draw lots for the scarce good. Race to the Top was President Obama's signature education initiative. It constituted a competitive grant program that rewarded states for demonstrating innovation in teacher certification and innovation.

Monies would be allocated only by lottery. This would ensure that potential recipients assemble and organize the desired governance structures -but not guarantee any monies. It worked for the Education thing. All the states scrambled to "compete" for the funds, but only 10 got monies.

\section{The Proposals}

Freeze current levels of per pupil spending. Any incremental monies allocated to education would be disbursed by lottery. To participate in the lottery, school districts will be asked to implement particular changes considered vital in closing the performance gap. These particular elements will collectively establish a qualification threshold.

Alternatively, one would identify all the "needy" school districts; select several by sortition. These latter alone are to be awarded incremental monies. A comparable amount is to be 
awarded to a few affluent school districts. In this manner we have set out an identification scheme that will provide empirical evidence as to the relevance of the underlying theory (Ayres, Listokin, \& Abramowicz, 2010).

A lottery's impartiality severs the link between the heuristic errors incurred in the appraisal of beliefs and in the appraisal of outcomes; it assuages the sentiment of unfairness for it is ex ante equitable. A lottery removes the costly armature imposed by interest groups on the process. Last, a lottery severs the inefficient path dependence of the existing administrative structures.

\section{Concluding Comments}

Adjudicating public education monies by lottery may strike some of us as somewhat callous. And upon reflection we may further conclude that considering such a process borders on an abdication of our moral responsibility to discharge - in Connecticut - a fundamental element of our social contract. The right to education is firmly embedded in our state constitution.(Note 16)

This faint (or vigorous, as the case might be) "revulsion" could be a misperception arising from many reasons including at least the following two. First, we could misunderstand allocation by lottery and, related, unintentionally discount its pervasiveness in our daily lives. Second, we fail to examine the attributes of allocation by lottery when set against the present allocation mechanism. It's not too difficult to see why we misunderstand the latter because it confounds many mechanisms at once. The present mechanism, a combination of a political process that badly aggregates education policy preferences, an institutional framework that enhances or facilitates rent-seeking and lends itself to strategic calculation resulting in what has become a viewers sport in Connecticut: the politics of race and ethnicity and the machinations of the powerful teachers' union. In these latter instances, resources wasted by the political process and the rent-seeking can easily absorb much or all of the surplus to be allocated.

\section{References}

Ayres, I., Listokin, Y. J., \& Abramowicz, M. (2010). Randomizing Law. Faculty Scholarship Series, Paper 161, 1-64.

Borges, J. L. (1998). The Lottery in Babylon. In J. L. Borges, Collected Fictions (pp. 101-106). New York, New York: Penguin Putnam.

Broome, J. (1984). Selecting People Randomly. Ethics, 95, 38-55. http://dx.doi.org/10.1086/292596

Calabresi, G., \& Bobbitt, P. (1978). Tragic Choices. New York, New York: W.W. Norton \& Co.

Carden, A. (2009). Can't Buy Me Growth: On Foreign Aid and Economic Change. The Journal of Private Enterprise, 25 (1), 105-123.

Chua, A. (2011, January 8-9). Why Chinese Mothers Are Superior. Wall Street Journal, pp. 
C-1.

CONNCAN. (2010). The State of Connecticut Public Education: 2009-2010. Hartford: Connecticut Coalition for Achievement Now (ConnCAN).

Connecticut Coaltion for Justice in Education Funding, Inc., et al. v. Governor M. Jodi Rell, SC 18032 (Connecticut Supreme Court March 30, 2010).

Currie, J. (2011, January). Inequality at Birth: Some Causes and Consequences. 1-48.

DeNardis, L. A. (2010). From Equity to Adequacy: Evolving Legal Theories in School Finance Litigation. The Case of Connecticut. International Journal of Education , 2 (1), 1-18.

DeNardis, L. A. (2010). Horton's Odyssey: The Politics of School Reform in Connecticut. New England Journal of Political Science, 4 (1), 237-281.

Dolle, J. R., \& Newman, A. (2008, June). Luck of the Draw? On the Fairness of School Charter Admission Policies.

Duxbury, N. (1999). Random Justice: On Lotteries and Legal Decision-Making. Oxford: Oxford University Press.

Dyson, M. R. (2004). Playing Games With Equality: A Game Theoretic Critique of Educational Sanctions, Remedies, and Strategic Noncompliance. Temple Law Review , 77, 577-639.

Easterbrook, F. (1984). The Limits of Antitrust. Texas Law Review, 63 (1), 1-40.

Eaton, S. (2006). The Children in Room E4. Chapel Hill, North Carolina: Algonquin Books.

Elster, J. (1989). Solomonic Judgments: Studies in the Limitations of Rationality. Cambridge: Cambridge University Press.

Epstein, R. A. (2008). Decentralized Responses to Good Fortune and Bad Luck. Theoretical Inquiries in Law, 9 (1), 308-341.

Epstein, R. A. (1988). Luck. Social Philosophy \& Policy, 17, 17-38. http://dx.doi.org/10.1017/S0265052500002661

Epstein, R. A. (1995). Simple Rules For A Complex World. Cambridge, Massachusetts: Harvard University Press.

Frahm, R. A. (2010, March 23). School decision presents another challenge to cash-strapped state. The Connectictut Mirror .

Frank, R. H. (1988). Passion Within Reason: The Strategic Role of Emotion. New York, New York: W.W. Norton \& Company.

Glass, R. D. (2006). Left Behind Once Again: What's Luck Got to Do wiht Current Education Policies and Practices? Philosophy of Education , 354-363.

Goodwin, B. (2005). Justice By Lottery. Exeter: Imprint Academic. 
Greely, H. (1977). The Equality of Allocation by Lot. Harvard Civil Rights-Civil Liberties Law Review , 12, 113-141.

Hammond, K. R. (1996). Human Judgment and Social Policy. New York, NY: Oxford University Press.

Hanushek, E. A. (2002). Publicly Provided Education. In A. J. Auerbach, \& M. Feldstein, Handbook of Public Economics. Amsterdan, The Nethelands: Elsevier Science.

Heiner, R. A. (1986). Uncertainty, Signal Detection Experiments and Modeling Behavior. In R. N. Langois, Economics as a Process (pp. 59-115). Cambridge: Cambridge University Press.

Hirshleifer, D. (2007). Psychological Bias as a Driver of Financial Regulation. MPRA Paper No. 5129 , 1-35.

Horton v. Meskill, 172 Conn. 615 (April 19, 1977).

Jackson, S. (2009). The Lottery. In S. Jackson, The Lottery and Other Stores. New York: Penguin Classics.

Kahneman, D. (2011, March). www.edge.org. [Online] Available: http://www.edge.org/q2011/q11_17.html\#kahneman (March 17, 2011)

Kahneman, D., \& Tversky, A. (1974). Judgment Under Uncertainty: Heuristics and Biases. Science , 185, 1124-31. http://dx.doi.org/10.1126/science.185.4157.1124

Kornhauser, L. A., \& Sager, L. G. (1988). Just Lotteries. Social Science Information, 27 (4), 483-516. http://dx.doi.org/10.1177/053901888027004001

Koski, W. S., \& Reich, R. (2006). When "Adequate" Isn't: The Retreat From Equity in Educational Law and Policy and Why It Matters. Emory Law Journal, 56 (3), 545-617.

Kunda, Z. (1987). Motivated Inference: Self-Serving Generation and Evaluation of Causal Theories. Journal of Personality and Social Psychology, 53, 636-647. http://dx.doi.org/10.1037/0022-3514.53.4.636

Kuran, T., \& Sunstein, C. R. (1999). Availability Cascades and Risk Regulation. Stanford Law Review, 51 (4), 683-768. http://dx.doi.org/10.2307/1229439

Lim, L. (2011, January 26). License Plate Lottery Meant to Curb Beijing Traffic. National Public Radio.

Little Hoover Commission. (1997). Dollars and Sense: A Simple Approach to School Finance. Sacramento: State of California.

Lockhard, A. A. (2003). Decision By Sortition: A Means to Reduce Rent-Seeking. Public Choice, 116, 435-451. http://dx.doi.org/10.1023/A:1024899605246

Lohman, J. (2005). Summary of Complaint in CCJEF v. Rell. Office of Legislative Research. Hartford: State of Connecticut. 
Manski, C. F. (2007). Identification for Prediction and Decision. Cambridge, MA: Harvard University Press.

March, J. G., \& Shapira, Z. (1987). Managerial Perspectives on Risk and Risk Taking. Management Science, 33 (11), 1404-1418. http://dx.doi.org/10.1287/mnsc.33.11.1404

Mauboussin, M. (2009). Sorting Luck from Skill. In M. Mauboussin, Think Twice (pp. 119-136). Boston, MA: Harvard Business Press.

Miller, H. I. (2010, Fall). Type I Terrors. Regulation, 30-33.

Mohl, B. (2004, July 22). Changes in High Risk Driver System to Hurt Poor, Consumer Group Says. The Boston Globe.

Nagel, T. (1976). Moral Luck. Proceedings of the Aristotelian Society, I.

Nisbett, R. E., \& Ross, L. (1980). Human Inference: Strategies and Shortcomings. Englewood Cliffs, New Jersey: Prentice Hall.

North, D. C. (1990). Institutions, Instutitional Change and Economic Performance. Cambridge: Cambridge University Press.

North, D. C. (2005). Understanding the Process of Economic Change. Princeton, New Jersey: Princeton University Press.

Posner, R. A. (1993). The Problems of Jurisprudence. Cambridge, MA: Harvard University Press.

Rhinehart, L. (2001). The Dice Man. Woodstock, New York: The Overlook Press.

Savage, S., \& Wainer, H. (2008). Until Proven Guilty: False Positives and the War on Terror. Chance , 21 (1), 59-62.

Schkade, D. A., \& Kahneman, D. (1998). Does Living in California Make People Happy? Psychological Science, 9 (5), 340-346. http://dx.doi.org/10.1111/1467-9280.00066

Schwartz, B. (2005, February 25). Top Schools Should Select Randomly from a Pool of 'Good Enough'. The Chronicle of Higher Education, 20-25.

Sheff v. O'Neill, 678 A.2d 1267, 1273 (Conn. 1996).

Sher, G. (1980). What Makes a Lottery Fair? Nous, 14, 203-215. http://dx.doi.org/10.2307/2214861

Simon, H. (1986). Rationality in Psychology and Economics. Journal of Business, 59 (4 pt. 2), S209-S224. http://dx.doi.org/10.1086/296363

Stewart, T. R. (2000). Uncertainty, Judgment and Error in Prediction. In D. Sarewitz, J. R. Pielke, \& J. R. Byerly, Prediction: Science, Decision Making, and the Future of Nature. Washington D.C.: Island Press.

Stone, P. (2009). The Logic of Random Selection. Political Theory, 37 (3), 375-397. 
http://dx.doi.org/10.1177/0090591709332329

Stone, P. (2010). Three Arguments for Lotteries. Social Science Information, 49 (2), 147-163. http://dx.doi.org/10.1177/0539018409359362

Stone, P. (2008). What Can Lotteries Do For Education? Theory and Research in Education, 6 (3), 267-282. http://dx.doi.org/10.1177/1477878508095583

Sunstein, C. (2000). Cognition and Cost-Benefit Analysis. The Journal of Legal Studies, 29 (2), 1059-1103. http://dx.doi.org/10.1086/468105

Sunstein, C. (1995). Foreword. In J. D. Graham, \& J. B. Wiener, Risk versus Risk (p. ix). Cambridge, MA: Harvard University Press.

Sunstein, C. R., Kahneman, D., Schkade, D., \& Ritov, I. (2001). Predicatably Incoherent Judgments. John M. Olin Law \& Economics Working Paper No. 131 , 1-65.

Swets, J. A. (1992). The Science of Choosing the Right Threshold in High Stakes Diagnostics. American Psychologist, 47, 522-532. http://dx.doi.org/10.1037/0003-066X.47.4.522

Symposium Connecticut Law Review, S. v. (1997, Spring). Sheff v. O'Neill Symposium. 29 , 3, 979-1365.

Taber, C. S., \& Lodge, M. (2006). Motivated Skepticism in the Evaluation of Political Beliefs. $\begin{array}{llrlll}\text { American Journal of Political } & \text { Science, } 50 & \text { (3), } & \text { 755-769. }\end{array}$ http://dx.doi.org/10.1111/j.1540-5907.2006.00214.x

Tversky, A., \& Kahneman, D. (1974). Judgment Under Uncertainty: Heuristics and Biases. Science, 185 (157), 1112-1131. http://dx.doi.org/10.1126/science.185.4157.1124

\section{Notes}

Note 1. The Constitution of the State of Connecticut was approved by referendum on December 14, 1965 and proclaimed as adopted on December 30, 1965.

Note 2. Article First, $\S \S 1$ of the constitution of Connecticut provides: "All men when they form a social compact, are equal in rights; and no man or set of men are entitled to exclusive public emoluments or privileges from the community." Article First, $\S \S 20$ provides "No person shall be denied the equal protection of the law nor be subjected to segregation or discrimination in the exercise or enjoyment of his civil or political rights because of religion, race, color, ancestry or national origin.” Article Eighth, $\S \S 1$,: There shall always be free public elementary and secondary schools in the state. The general assembly shall implement this principle by legislation. http://www.ct.gov/sots/cwp/view.asp?a=3188\&q=392288 (viewed January 2011).

Note 3. Sheff v. O'Neill, 238 Conn. 1, 678 A.2d 1267 (1997); Connecticut Coalition for Justice v. Rell, 990 A. 2d 206 - Conn: Supreme Court (2010).

Note 4. For example, plaintiffs in CCJEF v. Rell claimed that the state violated (1) article eighth, § 1, article first, $\S 1$ and $\S 20$ of the Connecticut Constitution. 
Note 5. The incremental increases in funding demanded by plaintiffs in CCJEF v. Rell, is unlikely to fall on favorable ears. There are several reasons for this. The claim arrives at a historically difficult time, one in which the state is facing billion dollar deficits. The state has not only increased tax burdens on its citizens to unprecedented levels but has been forced to reduce the level of taxpayer services.

Note 6. In its coverage of the Court's decision in CCJEF, the Connecticut Mirror characterized plaintiff's objective as "hoping to force the state to pump billions of dollars more into its public schools," and predicted its probable lack of success by quoting a state legislator partial to CCJEF's effort that, "fixing it, especially in today's economic climate, will be extremely difficult (Frahm, 2010).”

Note 7. The achievement gap refers to the disparity in the performance of groups of students often defined by gender, race, ethnicity and income statues, as determined by standardized measures.

Note 8. Bulletin of Yale University: 2009-2010, Series 105, Number 9, August 10, 2009. Note: Yale Law School, through its Education Adequacy Project was an instrumental participant in plaintiff's case. [Through litigation and advocacy, CCJEF seeks to reform Connecticut's public school finance system by substantially increasing funding and accountability such that all children are provided an adequate and substantially educational opportunity. ] at 29.

Note 9. Connecticut Television Network (CTN) CNB (Capitol News Briefing) with Bridgeport Legislative Delegation (December16, 2010) http://www.ctn.state.ct.us/ctn_web.asp; statement by Assemblyman Anthony Musto (D) Bridgeport.

Note 10. However, plaintiffs in CCJEF $v$ Rell span the state; when the complaint was filed they resided in Bridgeport, Danbury, Willimantic, Hartford, New Haven, East Hartford, New London, Plainfield and New Britain (footnote 3).

Note 11. DeNardis, Lesley, "Horton's Odyssey: The Politics of School Finance Reform in Connecticut,” New England Journal of Political Science, V 4, No. 2 (2010): 237-281. [The lion's share of the policy failure rests with the Connecticut General Assembly. As the body prompted by court decisions to design an equalization plan, much of the responsibility can be squarely placed at the legislature's doorstep. While the design of the equalization plans differed depending on whether Democrats or Republicans controlled the General Assembly, what did not differ greatly was the tendency through the time period under review was a notable reluctance e to fully fund equalization schemes. Both political parties seemed to be equally concerned with cost containment yielding to important political realities. Gubernatorial inaction, legislative recalcitrance and looming financial and fiscal realities all conspired to doom school finance reform in Connecticut; at 275.]

Note 12. To be sure, the presence of the gold standard in the calibration stage does not ensure the instruments performance when actually deployed in the field.

Note 13. Amy Chua, writing in the Wall Street Journal on the educational philosophy of 


\section{Macrothink}

International Journal of Education

ISSN 1948-5476

2011, Vol. 3, No. 2: E14

Chinese parents - a philosophy she shares puts it as follows: "Chinese parents demand perfect grades because they believe that their child can get them. If their child doesn't get them, the Chinese parent assumes it’s because the child didn’t work hard enough.”

Note 14. Citing Kunda (Kunda, 1987).

Note 15. The word good is used in its sense of referring or alluding to a commodity. Indeed, lotteries have been used to allocate "bads;" compulsory military service during wartime, for example, may have not been considered a good, in the normal usage of the word. Recall also the lot of Jonah, in scripture. (Jonah 1:6).

Note 16. (Horton v. Meskill 1977)

\section{Copyright Disclaimer}

Copyright reserved by the author(s).

This article is an open-access article distributed under the terms and conditions of the Creative Commons Attribution license (http://creativecommons.org/licenses/by/3.0/). 